\title{
OPEN Light absorption enhancement in ultrathin film solar cell with embedded dielectric nanowires
}

\author{
Mahmoud A. Elrabiaey ${ }^{1}$, Mohamed Hussein ${ }^{1,2}$, Mohamed Farhat O. Hameed ${ }^{1,3,4 \bowtie} \&$ \\ Salah S. A. Obayya ${ }^{1 凶}$ \\ A novel design of thin-film crystalline silicon solar cell (TF C-Si-SC) is proposed and numerically \\ analyzed. The reported SC has $1.0 \mu \mathrm{m}$ thickness of C-Si with embedded dielectric silicon dioxide \\ nanowires (NWs). The introduced NWs increase the light scattering in the active layer which improves \\ the optical path length and hence the light absorption. The SC geometry has been optimized using \\ particle swarm optimization (PSO) technique to improve the optical and electrical characteristics. \\ The suggested TF C-Si-SC with two embedded NWs offers photocurrent density $\left(J_{p h}\right)$ of $32.8 \mathrm{~mA} \mathrm{~cm}^{-2}$ \\ which is higher than $18 \mathrm{~mA} \mathrm{~cm}{ }^{-2}$ of the conventional thin film SC with an enhancement of $82.2 \%$. \\ Further, a power conversion efficiency of $15.9 \%$ is achieved using the reported SC.
}

The solar power, is considered as the best abundant and non-polluting renewable energy source. Due to its abundance, non-toxicity and mature fabrication technology, silicon solar cell (SC) shares $90 \%$ from photovoltaic market investment ${ }^{1}$. The power conversion efficiency (PCE) of crystalline silicon (C-Si) SCs has reached the plateau region and its highest value approaches the theoretical limit of $27.6 \%{ }^{2}$. To reduce the cost per watt, new generations of SCs have been introduced ${ }^{1,2}$. Thin film (TF) Si SC with active layer thickness of $1 \mu \mathrm{m}$ is an economical solution for solar energy harvesting with low cost ${ }^{1}$. However, TF technology suffers from lower absorption coefficients at longer wavelengths. Further, the thickness is small to trap the light through the active layer. Therefore, the absorption and power conversion efficiencies will be reduced. In order to increase the light path length inside the active layer, several nanostructures have been employed such as surface texture ${ }^{1,3,4}$, plasmonic nanoparticles ${ }^{1}$, and nanowire ${ }^{5}$.

Recently, the dielectric nanoparticles are used to improve the optical absorption and the generated photocurrent in TF C-Si-SCs ${ }^{6-10}$. The scattering cross sections of the dielectric nanoparticles are smaller than those of plasmonic nanoparticles. However, the dielectric nanoparticles have an incomparable low light absorption than that of plasmonic materials. Moreover, the active layer with plasmonic nanoparticles suffers from electrical degradation, owing to the plasmonic high surface recombination velocity (SRV) $\left(10^{6} \mathrm{~cm} \mathrm{~s}^{-1}\right)$ at the Si/plasmonic interface ${ }^{7}$. Nunomur et al. ${ }^{6}$ have introduced tandem SC with embedded $\mathrm{SiO}_{2}$ nano-spheres with an enhancement of $16 \%$ in the short-circuit current density $\left(J_{s c}\right)$. Mopourisetty et al. ${ }^{7}$ have reported an electrical study for $1 \mu \mathrm{m}$ TF C-Si-SC with surface recombination losses at a $\mathrm{Si} / \mathrm{SiO}_{2}$ interface with a $J_{s c}$ of $11.9 \mathrm{~mA} \mathrm{~cm}{ }^{-2}$. Yang et al. ${ }^{8}$ have introduced $2 \mu \mathrm{m}$ TF C-Si-SC with partially embedded dielectric sphere with a photocurrent density $\left(J_{p h}\right)$ and $J_{s c}$ of $30.09 \mathrm{~mA} \mathrm{~cm}^{-2}$ and $28.6 \mathrm{~mA} \mathrm{~cm}^{-2}$, respectively. Further, Nagel et al. ${ }^{9}$ have improved the light trapping using embedded silicon dioxide $\left(\mathrm{SiO}_{2}\right)$ nanospheres in TF-SC. Such a structure offers an absorption enhancement of $23.4 \%$ relative to the conventional SC.

In this work, we propose and analyze a new design approach for enhancing the efficiency of TF-SCs with a thickness of $1 \mu \mathrm{m}$. The suggested technique is based on lateral scattering using dielectric nanowires embedded within the active layer. Such dielectric nanowires are nearly lossless with high cross-sectional scattering along their length which can improve the SC efficiency. In this study, the $\mathrm{SiO}_{2}$ is used as a scatter element due to the

\footnotetext{
${ }^{1}$ Centre for Photonics and Smart Materials, Zewail City of Science and Technology, October Gardens, 6th of October City, Giza 12578, Egypt. 'Department of Physics, Faculty of Science, Ain Shams University, Abbassia 11566, Cairo, Egypt. ${ }^{3}$ Nanotechnology and Nanoelectronics Engineering Program, University of Science and Technology, Zewail City of Science and Technology, October Gardens, 6th of October City, Giza 12578, Egypt. ${ }^{4}$ Mathematics and Engineering Physics Department, Faculty of Engineering, Mansoura University, Mansoura 35516, Egypt. ${ }^{\circledR}$ email: mfarahat@zewailcity.edu.eg; sobayya@zewailcity.edu.eg
} 


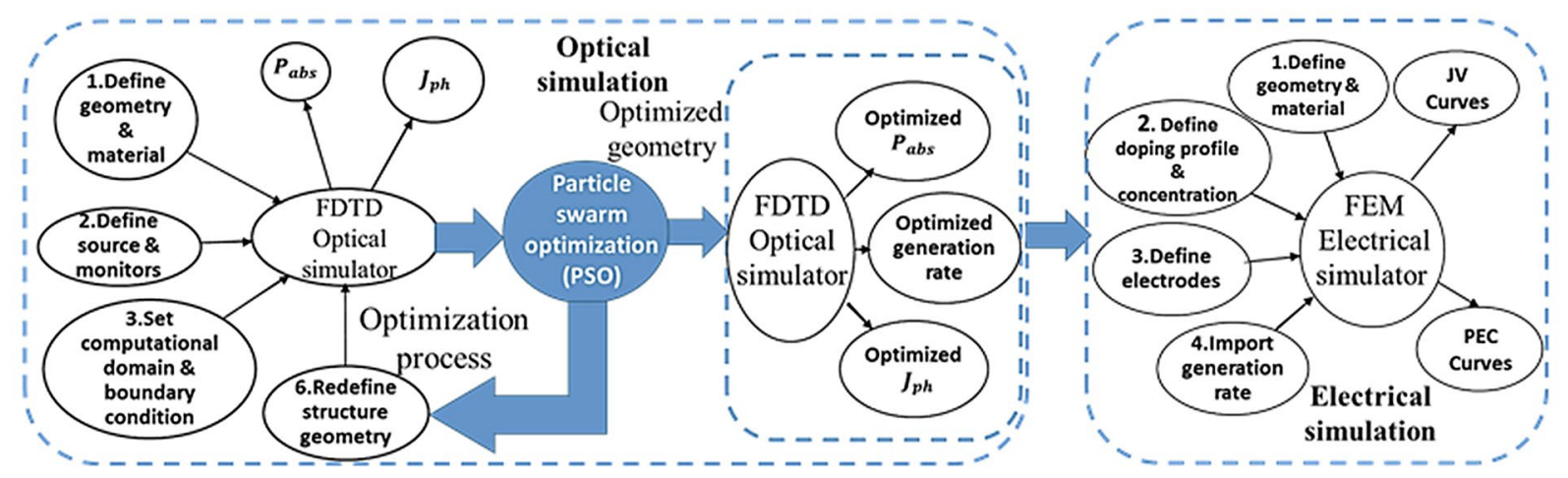

Figure 1. Simulation strategy of the proposed design using optical FDTD and electrical FEM simulators.

large index contrast with the $\mathrm{Si}$ material $(\mathrm{n}=3.6)$. Additionally, the $\mathrm{SiO}_{2}$ is almost perfectly lossless within the visible spectrum. Under the right circumstances, $\mathrm{Si} / \mathrm{SiO}_{2}$ interfaces may have extremely low interface recombination velocities and dangling bond densities. Further, the growth of $\mathrm{SiO}_{2} \mathrm{NWs}$ can be implemented using oxidation process of $\mathrm{Si}^{10}$. The modified TF-SC with two embedded dielectric NWs offers power conversion efficiency (PCE) of $15.9 \%$ and an optical absorption enhancement of $82.2 \%$ over the conventional planer TF SC.

\section{Simulation strategy}

Figure 1 shows the simulation strategy for the SC characterization. First, optical studies are carried out by using 3D finite-difference time-domain (FDTD) via Lumerical software package to calculate the optical absorption $\left(P_{a b s}\right)$ and $J_{p h}{ }^{11}$. To estimate the absorption capability of the TF C-Si-SCs, $J_{p h}$ is calculated under air mass 1.5 (AM $1.5 \mathrm{G})$ solar spectrum. To further enhance the $P_{a b s}$ and $J_{p h}$ of the reported design, the geometrical parameters are optimized using particle swarm optimization (PSO) technique ${ }^{12}$. In this investigation the $J_{p h}$ is used as a fitness function of the PSO algorithm to quantify the broadband absorption capability of the suggested TF C-Si-SC ${ }^{5}$ :

$$
J_{p h}=\frac{e}{h c} \int_{300}^{1100} \lambda \phi_{A M 1.5}(\lambda) P_{a b s}(\lambda) d \lambda
$$

where $e$ is the electron unit charge, $\mathrm{h}$ is the Plank constant, $c$ is the light speed in vacuum, $\Phi_{A M 1.5}$ is the solar spectral irradiance AM 1.5 as obtained from the NREL database ${ }^{2}$ and $P_{a b s}$ is the optical absorption spectrum of the C-Si material.

Next, the generation rate of the optimal design is imported into the electrical simulator to quantify the photo-generated electron-hole pairs that can be collected and contributed to the output electrical power. The electrical model is used to calculate both the PCE and $J_{s c}$ using finite element method (FEM) via Lumerical device simulation package ${ }^{11}$.The FEM package solves coupled nonlinear equations of semiconductor (drift-diffusion equations and Poisson continuity) to obtain the power conversion efficiency (PCE) of the reported design ${ }^{13-15}$. The PCE can be calculated according to the following equation ${ }^{7}$ :

$$
P E C=\frac{F \cdot F \times J_{s c} \times V_{o c}}{P_{\text {in }}}
$$

where $P_{\text {in }}$ is the incident power at AM 1.5, F.F is the fill factor defined as $\left(F . F=P_{\max } / J_{s c} \times V_{o c}\right), V_{o c}$ is the open-circuit voltage, and $P_{\text {max }}$ is the maximum power.

\section{Design consideration and numerical results}

Figure $2 \mathrm{a}-\mathrm{c}$ show the schematic diagram of the planar TF-SC, TF-SC with embedded dielectric sphere and embedded nanowire, respectively. The embedded dielectric $\left(\mathrm{SiO}_{2}\right)$ sphere and $\mathrm{NW}$ have the same volume and are positioned at $450 \mathrm{~nm}$ from the surface. The sphere and the NW have the same diameter of $200 \mathrm{~nm}$ as shown in Fig. 2b,c. Further, the nanowire has a length (L) of $133 \mathrm{~nm}$. The proposed design is optically simulated using computational domain of $750 \mathrm{~nm} \times 750 \mathrm{~nm}$ with height of $3 \mu \mathrm{m}$ with minimum mesh size of $8.0 \mathrm{~nm}$. In addition, periodic boundary conditions are used in the $\mathrm{x}$ and $\mathrm{y}$-directions to mimic the effects of an infinitely periodic unit cell. However, the boundary condition along $\mathrm{z}$ axis is a perfect matched layer (PML). The suggested design is excited from the top by a plane wave with wavelength range from 300 to $1100 \mathrm{~nm}$. The material refractive indices of silicon and silicon dioxide are predefined in the Lumerical material database based on Palik's model ${ }^{16}$.

The TF-SC design with embedded dielectric $\left(\mathrm{SiO}_{2}\right)$ sphere is previously published $\mathrm{in}^{9}$. The power absorption of the planar TF-SC, TF-SC with embedded dielectric sphere ${ }^{9}$ and embedded NW is shown in Fig. $2 \mathrm{~d}$. It can be seen from this figure that the TF-SC with dielectric scatter has higher absorption than the baseline TF-SC counterpart. Figure $2 \mathrm{e}$ illustrates the $J_{p h}$ and the absorption efficiency $(\eta)$ for the three studied designs. It can be seen from this figure that the TF-SC with sphere and NW scatters have $J_{p h}$ and $\eta$ higher than that of the conventional base line counterpart. The $J_{p h}$ for the planar TF-SC and TF-SC with embedded dielectric sphere and nanowire are equal to $17.73,21.9$, and $24.6 \mathrm{~mA} \mathrm{~cm}^{-2}$, respectively. Additionally, $\eta$ of the planar TF-SC and 


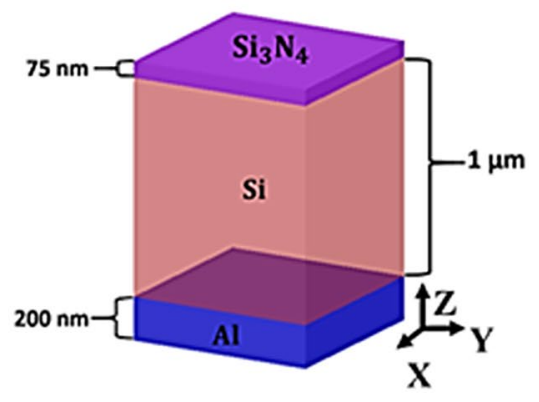

(a)

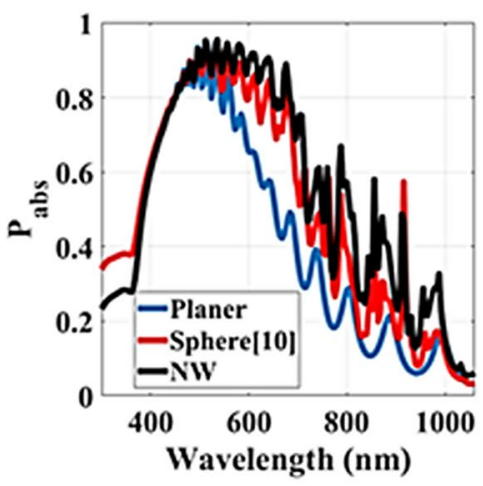

(d)

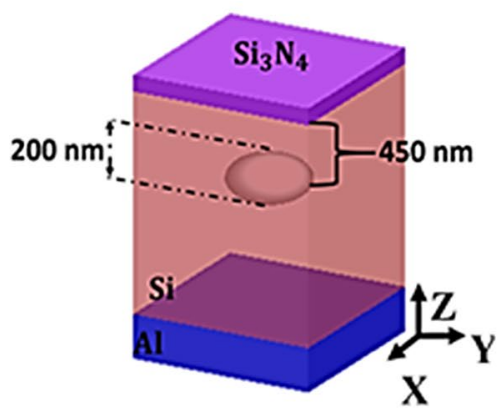

(b)

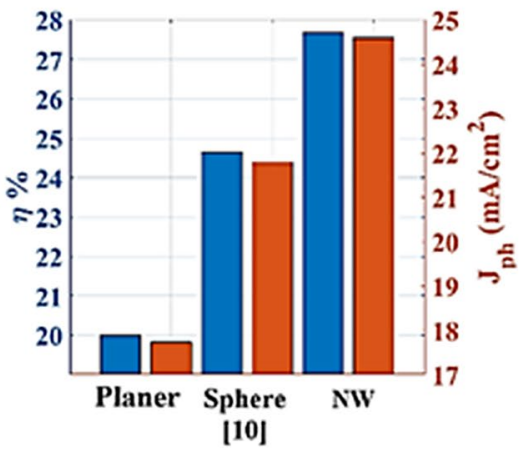

(e)

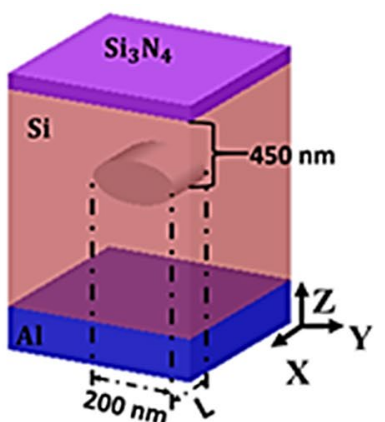

(c)

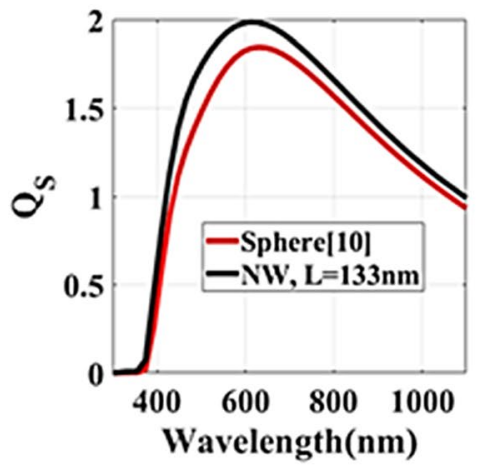

(I)

Figure 2. Schematic diagram of (a) planer SC, (b) SC with embedded dielectric sphere, and (c) SC with embedded dielectric NW of length (L). (d) The power absorption of the planar TFSC and TFSC with dielectric sphere and TF-SC with dielectric $\mathrm{SiO}_{2} \mathrm{NW},(\mathbf{e})$ the $J_{p h}$ and the absorption efficiency $(\eta)$ for the studied designs, and (f) the scattering efficiency of the $\mathrm{SC}$ with embedded $\mathrm{SiO}_{2}$ sphere ${ }^{9}$ and $\mathrm{NW}$ of the same volume at the same depth. This image is created by Lumerical 2020a, FDTD Solver Version 8.23.2305, https://www.lumerical.com (license number-12802) released to Zewail City of Science and Technology, Giza, Egypt.

TF-SC with embedded dielectric sphere and nanowire are equal to $20 \%, 24.65 \%$, and $27.674 \%$, respectively. This enhancement is attributed to the cylindrical geometry of the NW which has a higher scattering efficiency than that of the spherical geometry by $10.9 \%$ especially at $\lambda \geq 500 \mathrm{~nm}$ as shown in Fig. $2 \mathrm{f}$. The scattering efficiency $\left(Q_{s}\right)$ is defined as the ratio between scattering cross-section of a dielectric particle and the physical cross-sectional area $^{9}$. Therefore, higher scattering is achieved for the incident light inside the active layer by the cylindrical NWs. Consequently, the absorption and $J_{p h}$ are enhanced. It is also expected that the two embedded NWs can further improve the light absorption.

Next, the coupled optical/electrical modeling techniques are used to explore the cell performance of the proposed SC with three dielectric embedded elements (sphere, single NW, and two NWs) and compered with the conventional baseline SC. These designs are optically simulated using computational domain of $1 \mu \mathrm{m} \times 1 \mu \mathrm{m}$ with height of $3 \mu \mathrm{m}$ with minimum mesh size of $8.0 \mathrm{~nm}$. Figure 3 shows 3D schematic diagram of the reported $1.0 \mu \mathrm{m}$ TF C-Si-SC with two embedded nanowires. The suggested design has an antireflection coating of $\mathrm{Si}_{3} \mathrm{~N}_{4}$ with a thickness of $75 \mathrm{~nm}^{9}$. Further, a trapezoidal grating is used as a back reflector with upper and lower bases of $L_{t u}$ and $L_{t b}$, respectively. The two embedded NWs have an elliptical shape with minor and major diameters of $d_{1}, d_{2}, d_{3}$, and $d_{4}$, respectively. The NWs are added in the active layer at a depth of $Z_{1}$ and $Z_{2}$ from the surface of the active layer with rotation angle of $\Theta_{\text {rod }}$ as shown in Fig. 3. In order to obtain the optimal design dimensions with maximum photocurrent density, the PSO technique is employed for the two embedded elements (single NW and two NWs). Table 1 summarizes the initial and optimized parameters of the reported design with one NW and two NWs cases. There are six optimization parameters which are minor, major diameters, the distance from the surface of the active layer and center of nanowire $\left(Z_{N W}\right)$, rotation angle of $\Theta_{\text {rod }}$ and the upper $\left(L_{t u}\right)$ and lower $\left(L_{t b}\right)$ bases of the trapezoid back grating etching. For single NW, $\Theta_{\text {rod }}$ is the angle between the NW and the $\mathrm{x}$-axis while for the two NWs $\Theta_{\text {rod }}$ represents the angle between them. The initial and optimized geometrical parameters are listed in Table 1.

Optical characterization. Figure 4a shows the optimization performance for the $J_{p h}$ of SCs with single/ double NWs versus the iterations number. The optimized design offers $J_{p h}$ of $30.2 \mathrm{~mA} \mathrm{~cm}^{-2}$ and $32.8 \mathrm{~mA} \mathrm{~cm}{ }^{-2}$, respectively which exceed the Lambertian limit for $1.0 \mu \mathrm{m} \mathrm{TF} \mathrm{C-Si-SC}{ }^{17}$. This enhancement is mainly attributed to the presence of embedded NWs as dielectric scatters. Therefore, an enhancement ratio of $67 \%$ and $82.2 \%$ respectively are achieved over the conventional planer TF C-Si-SC. It may be also seen from this figure that the optimizer has fast convergence with smaller iteration numbers using two NWs. The improvement in $J_{p h}$ 


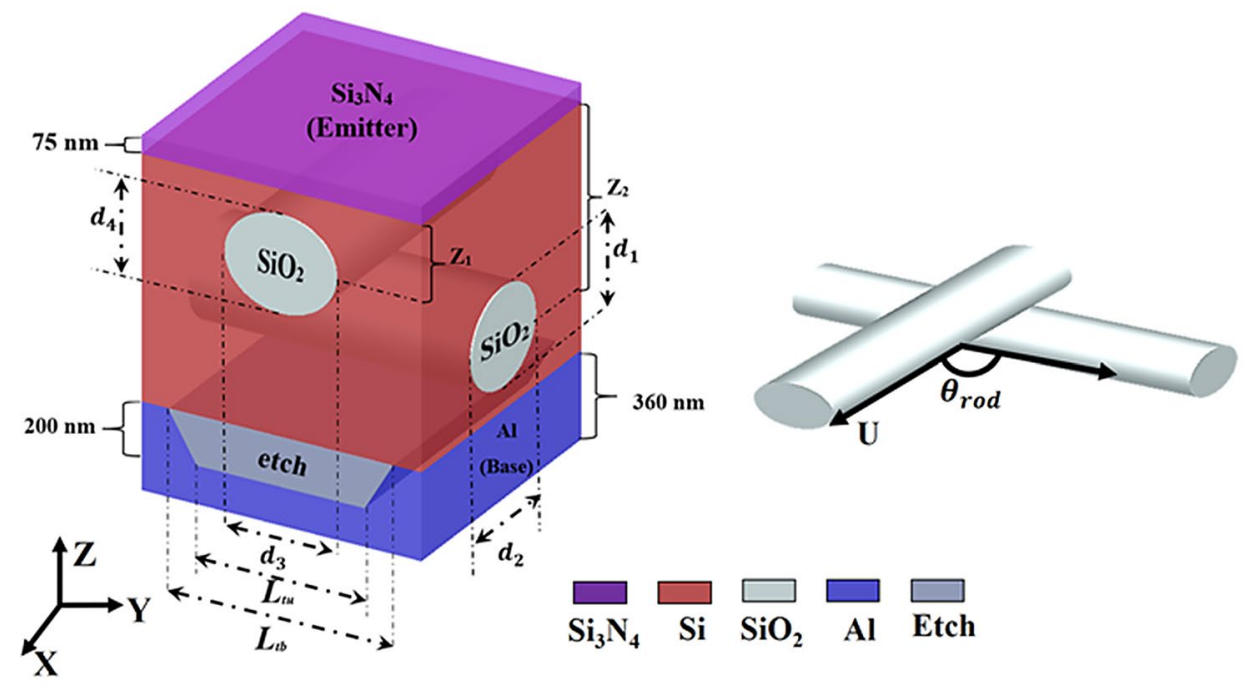

Figure 3. Schematic diagram of the proposed design with two dielectric nanowires (NWs). This image is created by Lumerical 2020a, FDTD Solver Version 8.23.2305, https://www.lumerical.com (license number-12802) released to Zewail City of Science and Technology, Giza, Egypt.

\begin{tabular}{|l|r|r|l|l|}
\hline \multirow{2}{*}{ Parameters } & \multicolumn{2}{l|}{ Decision space } & \multicolumn{2}{l|}{ Optimum values } \\
\cline { 2 - 5 } & From & To & 1 NW & 2 NWs \\
\hline $\mathrm{d}_{1}$ & $200 \mathrm{~nm}$ & $400 \mathrm{~nm}$ & $200 \mathrm{~nm}$ & $200 \mathrm{~nm}$ \\
\hline $\mathrm{d}_{2}$ & $200 \mathrm{~nm}$ & $400 \mathrm{~nm}$ & $302 \mathrm{~nm}$ & $200 \mathrm{~nm}$ \\
\hline $\mathrm{d}_{3}$ & $200 \mathrm{~nm}$ & $400 \mathrm{~nm}$ & - & $248 \mathrm{~nm}$ \\
\hline $\mathrm{d}_{4}$ & $200 \mathrm{~nm}$ & $400 \mathrm{~nm}$ & - & $200 \mathrm{~nm}$ \\
\hline$\Theta_{\text {rod }}$ & $0^{\circ}$ & $90^{\circ}$ & $20.8^{\circ}$ & $72.62^{\circ}$ \\
\hline $\mathrm{Z}_{1}$ & $-200 \mathrm{~nm}$ & $200 \mathrm{~nm}$ & $100 \mathrm{~nm}$ & $336 \mathrm{~nm}$ \\
\hline $\mathrm{Z}_{2}$ & $-200 \mathrm{~nm}$ & $200 \mathrm{~nm}$ & - & $536 \mathrm{~nm}$ \\
\hline$L_{t u}$ & 0 & $900 \mathrm{~nm}$ & $900 \mathrm{~nm}$ & $900 \mathrm{~nm}$ \\
\hline$L_{t b}$ & 0 & $900 \mathrm{~nm}$ & $872 \mathrm{~nm}$ & $900 \mathrm{~nm}$ \\
\hline
\end{tabular}

Table 1. The initial and optimized geometrical parameters of the proposed $\mathrm{SC}$ with embedded $\mathrm{SiO}_{2} \mathrm{NWs}$.

is due to cylindrical geometry of the NWs that offers a degree of freedom through NW length (L) variation. Figure $4 \mathrm{~b}$ shows the scattering efficiencies of the embedded dielectric sphere and NWs with multiple lengths $(L, 2 \times L, 3 \times L, 4 \times L$, and $5 \times \mathrm{L})$. The dielectric elements have a diameter of $200 \mathrm{~nm}$ at a depth of $450 \mathrm{~nm}$ beneath the $\mathrm{C}-\mathrm{Si} / \mathrm{Si}_{3} \mathrm{~N}_{4}$ interface ${ }^{9}$. The scattering efficiency is improved by increasing the length $\mathrm{L}$ especially at $\lambda \geq 500 \mathrm{~nm}$. This enhancement is attributed to the NW length (characteristic length) which increases the scattering in the horizontal direction compared to spherical counterpart.

Figure $4 \mathrm{c}$ shows the $P_{a b s}$ of the conventional planer TF C-Si-SC (baseline), TF C-Si-SC with embedded $\mathrm{SiO}_{2}$ nano-spheres ${ }^{9}$, single $\mathrm{SiO}_{2} \mathrm{NWs}$, and two $\mathrm{SiO}_{2} \mathrm{NWs}$. It may be seen from this figure that the $\mathrm{SiO}_{2}$ scatter will enhance the optical absorption compared to the planar reference SC device. As $\lambda$ increases further than $450 \mathrm{~nm}$, $P_{a b s}$ of the planar device is decreased due to the low absorption coefficient of C-Si material at mid and high wavelength band ${ }^{8,9}$. However, by introducing the embedded NWs, the absorption enhancement is increased rapidly in the mid and high wavelength band owing to the geometry and configuration of the nanowires. Additionally, due to the improved impedance mismatch between the air and C-Si layer, more scattering occurs through the active layer with more light absorption. The $J_{p h}$ of the planer conventional TF-SC, TF-SC with embedded nanospheres, one and two NWs are 18.3, 25.9, 30.2 and $32.8 \mathrm{~mA} \mathrm{~cm}^{-2}$, respectively.

Figure $5 \mathrm{~b}$ illustrates the normalized absorption distribution at cross sectional plane ZU shown in Fig. $5 \mathrm{a}$. It may be seen that the light is highly trapped and absorbed below the NWs. For further investigation, another monitor is placed along the side plane (ZX) for the NWs as shown in Fig. 5c. The normalized absorption distributions at the edges of the TF C-Si-SCs is described in Fig. $5 \mathrm{~d}$ where the light path is plotted red dotted line. Such figures confirm that the presence of NWs produces volume light scattering in the active layer which improves the optical absorption by tuning the scattering mean free path to the material absorption length. 


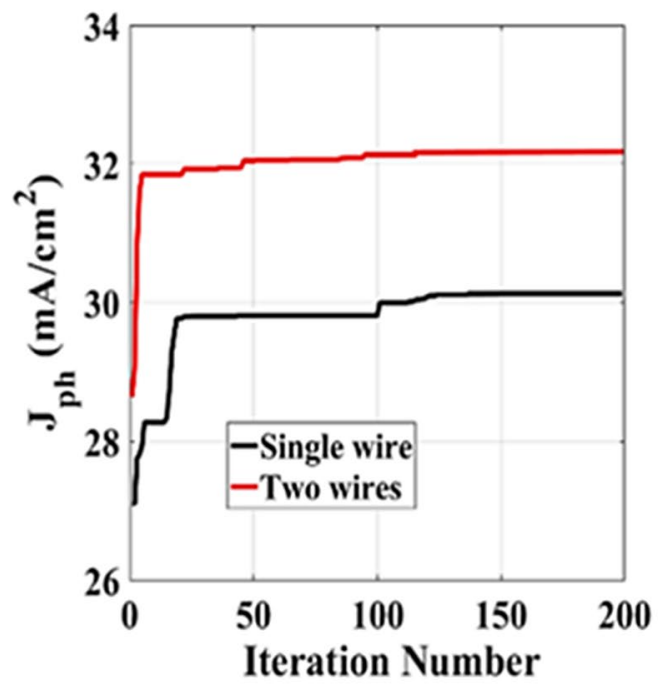

(a)

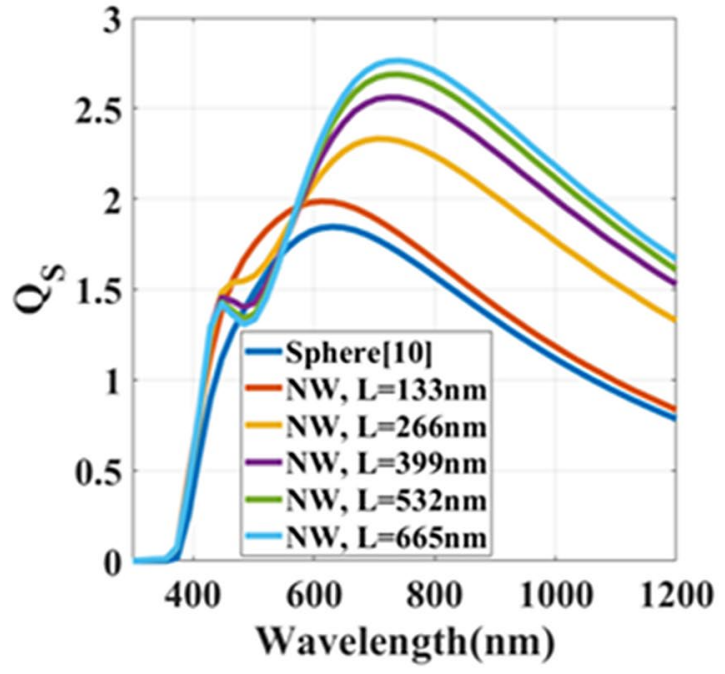

(b)

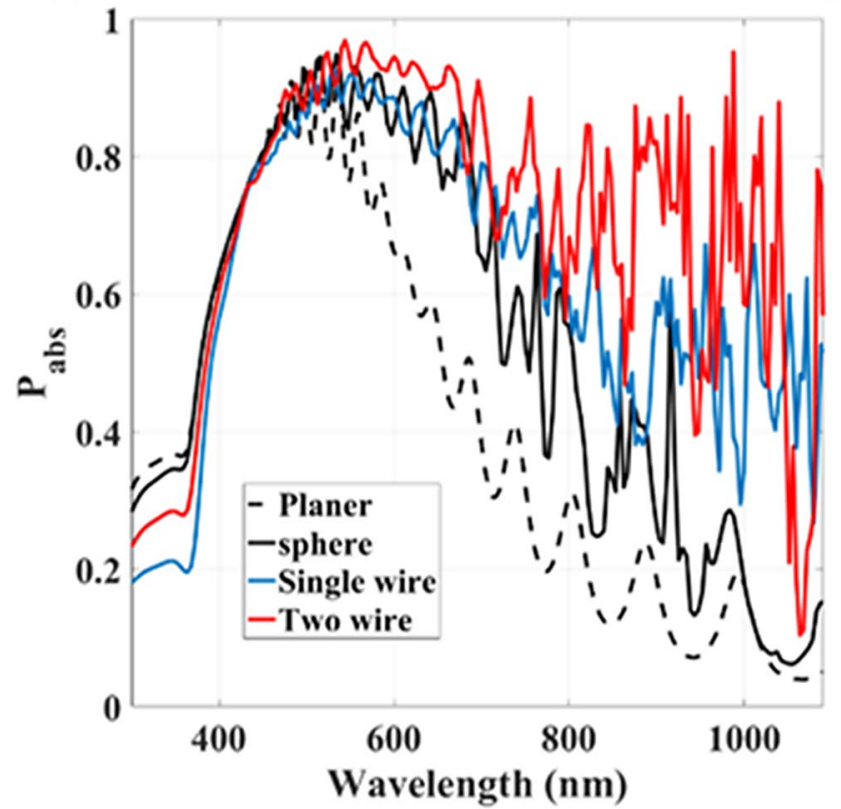

(c)

Figure 4. (a) The FOM trend of the PSO optimization for the single NW and the two NWs design, (b) the scattering efficiency as a function of the NW length (L), and (c) the absorption spectra of planer TF-SC (dotted line), TF-SC with embedded sphere ${ }^{9}$ (black line), and proposed design with single NW (blue line), and with two NWs (red line).

Figure 6a shows a schematic diagram of the reported SC with embedded two NWs under the excitation of transverse electric (TE) and transverse magnetic (TM) modes. In this study, the incident angle $(\beta)$ for both excitation modes is swept from $-50^{\circ}$ to $50^{\circ}$. Figure $6 \mathrm{~b}$ shows the photon current density $J_{p h}$ versus the incidence angle for TE and TM polarizations. It may be seen from Fig. $6 \mathrm{~b}$ that the $J_{p h}$ for TE and TM modes are nearly the same at normal incidence $\left(\beta=0^{\circ}\right)$ and is equal to $32.9 \mathrm{~mA} \mathrm{~cm}^{-2}$. Additionally, a second maximum of $J_{p h}$ is achieved at $\beta=30^{\circ}$ which is equal to 29.5 and $25.4 \mathrm{~mA} \mathrm{~cm}^{-2}$ for TE and TM excitations, respectively. The angular photocurrent response can be explained by the polarization angle effect. At the incident angle $(\beta)=0^{\circ}$, the light is nearly fully transmitted into the absorber without any reflection ${ }^{18}$. At $\beta=30^{\circ}$, the absorption enhancement is due to the increment of the optical path length in addition to the angular scattering from the two NWs. The difference between the $J_{p h}$ according to the TE and TM modes is due to the asymmetry of the two NWs in y-axis and $\mathrm{x}$-axis. In this context, the tilted incident angle will increases the influence of the asymmetry of the NWs ${ }^{18}$.

Electrical characterization. Figure 7a shows the schematic diagrams of the reported TF-SC with p-i-n doping (p-type/intrinsic/n-type) mounted on Si substrate. The proposed design utilizes the silicon nitrate and aluminum as the emitter and base electrodes, respectively as shown in Fig. 7a. In this study, the doping concentrations of $\mathrm{P}^{+}$and $\mathrm{N}^{+}$regions are equal to $5 \times 10^{17}$ and $1 \times 10^{19} \mathrm{~cm}^{-3}$, respectively ${ }^{8,19}$. However, the doping $\mathrm{P}^{+}$and 


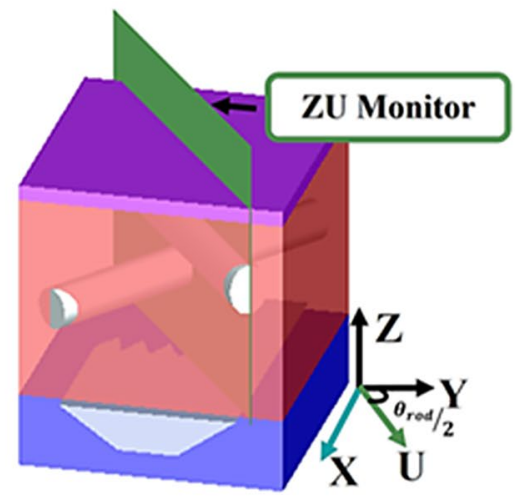

(a)

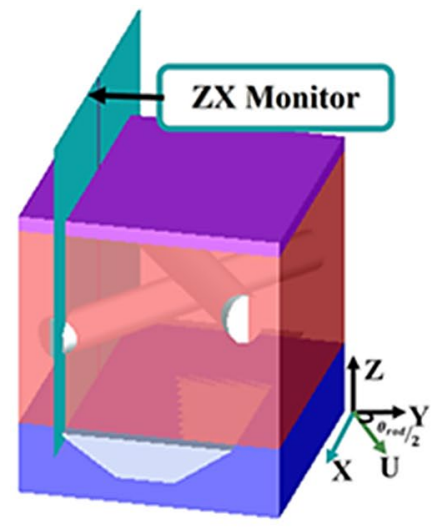

(c)

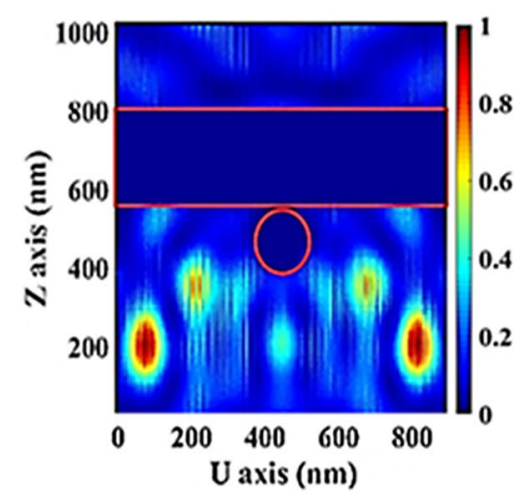

(b)

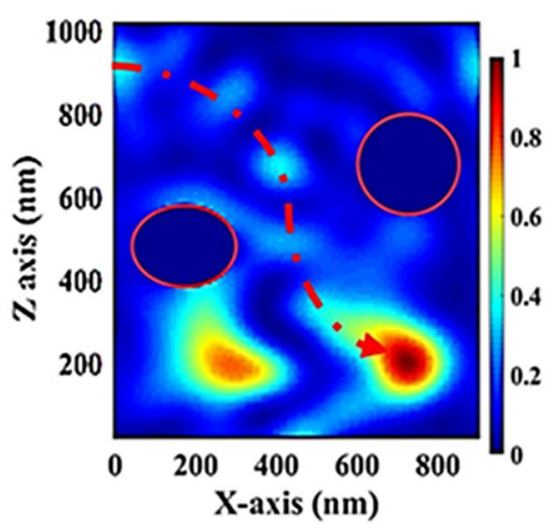

(d)

Figure 5. (a) Schematic diagram of proposed design with two NWs at the diagonal plane (ZU), (b) the normalized absorption distributions at cross section plane $(Z U)$, (c) schematic diagram of the suggested design with two dielectric nanowires (NWs) at the side plane (ZX), and (d) the normalized absorption distributions for the two NWs at cross sectional plane (ZX). This image is created by Lumerical 2020a, FDTD Solver Version 8.23.2305, https://www.lumerical.com (license number-12802) released to Zewail City of Science and Technology, Giza, Egypt.

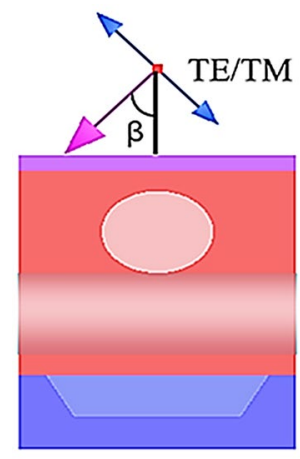

(a)

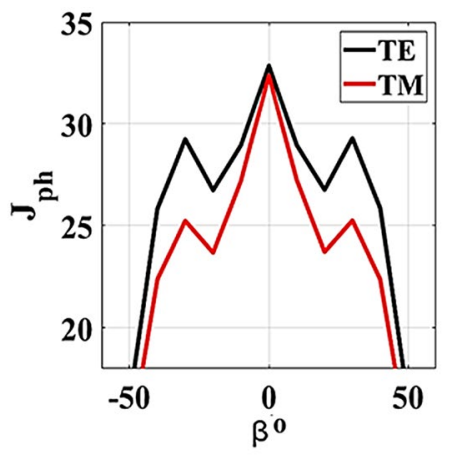

(b)

Figure 6. (a) Schematic diagram of the optimized design with NWs with an oblique incidence; and (b) the angular photocurrent response under TE and TM incidences for the two NWs C-Si-SCs. This image is created by Lumerical 2020a, FDTD Solver Version 8.23.2305, https://www.lumerical.com (license number-12802) released to Zewail City of Science and Technology, Giza, Egypt. 


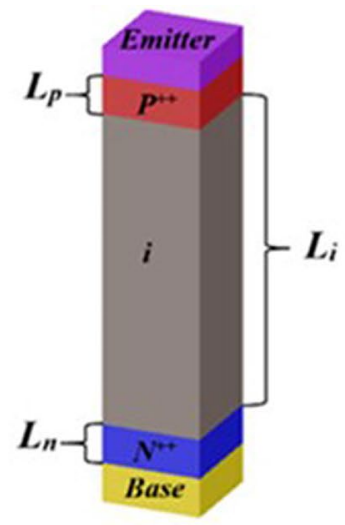

(a)

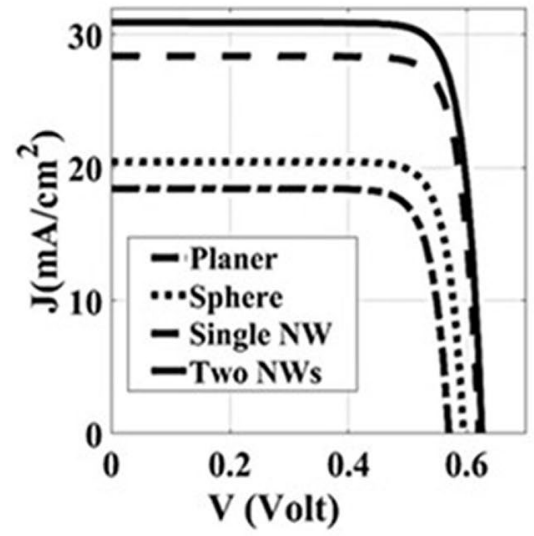

(c)

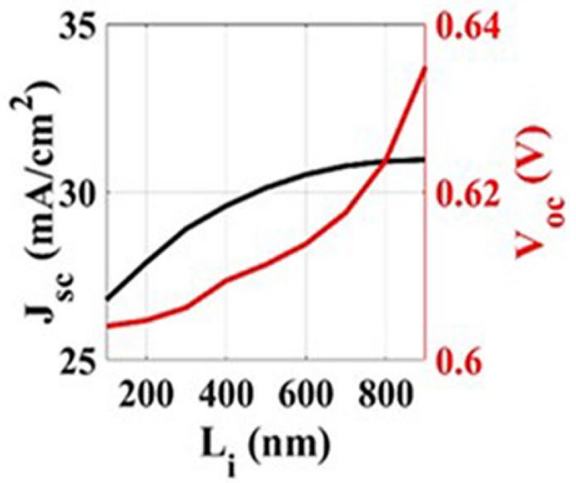

(b)

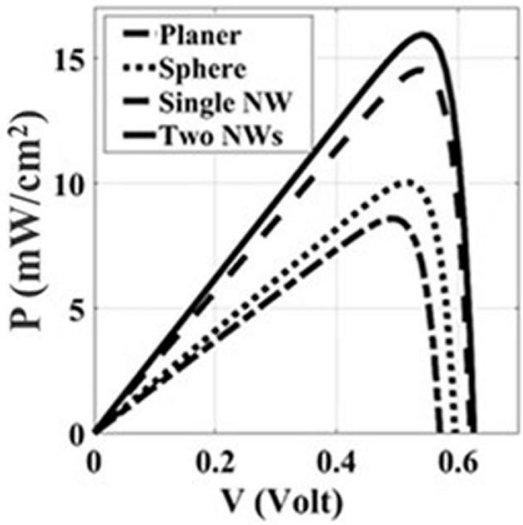

(d)

Figure 7. (a) The $\mathrm{p}-\mathrm{i}-\mathrm{n}$ axial doping, (b) the $\mathrm{J}_{\mathrm{sc}}$ and $\mathrm{V}_{\mathrm{oc}}$ dependence on the $\mathrm{L}_{\mathrm{i}}$, (c) $\mathrm{J}-\mathrm{V}$ characteristics of the C-Si TF planer and with different embedded dielectric elements: sphere, single NW, and two NWs, and (d) power density curves for C-Si TF planer and with different embedded dielectric elements: sphere ${ }^{9}$, single NW, and two NWs.

\begin{tabular}{|l|l|l|l|l|}
\hline Dielectric element & $\mathbf{V}_{\text {oc }}(\mathbf{V})$ & $\mathbf{J}_{\text {sc }}\left(\mathbf{m} \mathbf{A ~ c m}^{-2}\right)$ & PCE (\%) & $\begin{array}{l}\text { F.F } \\
(\mathbf{\%})\end{array}$ \\
\hline Planer & 0.57 & 18.425 & 8.58 & 82 \\
\hline Sphere & 0.584 & 20.44 & 10.1 & 82.52 \\
\hline Single NW & 0.614 & 28.3 & 14.48 & 83.3 \\
\hline Two NWs & 0.623 & 30.91 & 15.91 & 83.01 \\
\hline
\end{tabular}

Table 2. The J-V characteristics of the TFC-Si-SCs with different embedded dielectric elements.

$\mathrm{N}^{+}$regions are on the front and rear part of the SCs with thicknesses of $\mathrm{L}_{\mathrm{p}}$ and $\mathrm{L}_{\mathrm{n}}$, respectively. Also, the carrier lifetimes of $\mathrm{P}^{+}, \mathrm{N}$, and $\mathrm{N}^{+}$region are 10,1000 , and $5 \mu$ s, respectively. The surface recombination velocity is $2 \times 10^{5} \mathrm{~cm} \mathrm{~s}^{-18}$. Additionally, the Auger coefficients for electrons and holes are $9.9 \times 10^{-32}$ and $2.2 \times 10^{-31} \mathrm{~cm}^{6} \mathrm{~s}^{-1}$, respectively ${ }^{19}$. The bimolecular radiative coefficient is also taken as $9.5 \times 10^{-15} \mathrm{~cm}^{3} \mathrm{~s}^{-119}$.

The thickness of the doping regions $\mathrm{L}_{\mathrm{i}}$ can be selected from Fig. $7 \mathrm{~b}$ in order to increase the conversion efficiency with a saturated $J_{s c}$ of $30.91 \mathrm{~mA} \mathrm{~cm}^{-2}$ at $\mathrm{L}_{\mathrm{i}}$ equals to $800 \mathrm{~nm}$. In this investigation, the thickness of $\mathrm{L}_{\mathrm{p}}$ and $\mathrm{L}_{\mathrm{n}}$ is equal to $100 \mathrm{~nm}$. Figure $7 \mathrm{c}$, d present an electrical comparison between three different embedded dielectric elements with the planer solar TF C-Si-SC. The dimensions of embedded single NW and two nanowires are mentioned in Table 1 . The calculated $J_{s c}$, the open-circuit voltage $\left(V_{o c}\right)$, PCE, and the fill factor (F.F) for the three embedded elements are listed in details in Table 2.

The enhancement in J-V characteristics for the proposed design with single NW and two NWs can be attributed to the absorption enhancement shown in Fig. 4c. Accordingly, it is expected that the (J-V) results of the proposed design show better electrical performance than that of others. It may be seen from $J$ values presented in 


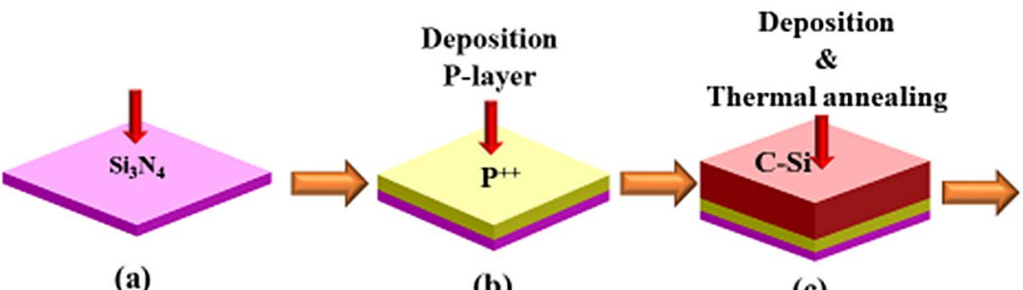

(a) (c)

\section{Deposition}

\&

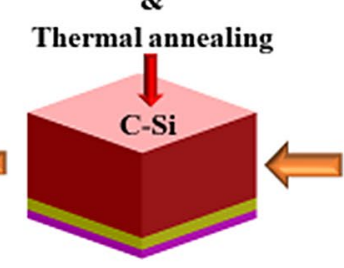

(h)

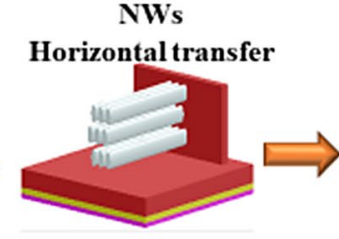

(d)

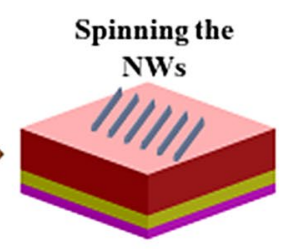

(e)

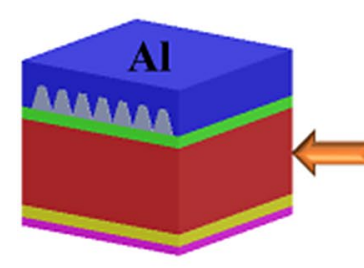

(j)

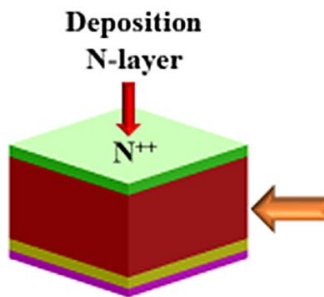

(i)

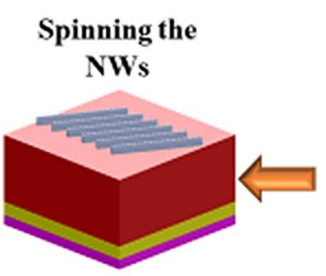

(g)

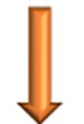

Deposition

$\mathcal{E}$

Thermal annealing

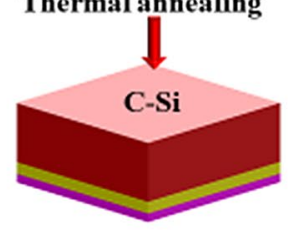

(f)

Figure 8. The deposition of (a) $\mathrm{Si}_{3} \mathrm{~N}_{4}$ and then (b) P++ doped Si layers; (c) deposition and annealing processes to form the C-Si; (d) etched substrate is vertically pressed onto the target substrate; (e) the $\mathrm{SiO}_{2} \mathrm{NWs}$ are transferred onto the target substrate; (f) deposition of the second C-Si layer; (g) the second batch of $\mathrm{SiO}_{2} \mathrm{NWs}$ is transferred onto the target substrate; (h) the third layer of $\mathrm{C}-\mathrm{Si}$ is then deposed and annealed; (i) deposition of the $\mathrm{n}++$ layer; and $(\mathbf{j})$ transfer of the aluminum grating layer. This image is created by Lumerical 2020a, FDTD Solver Version 8.23.2305, https://www.lumerical.com (license number-12802) released to Zewail City of Science and Technology, Giza, Egypt.

Fig. 7c that the reported design with embedded two NWs and single NW have higher $J_{s c}$ than that of nanosphere and planer based TF C-Si-SC which are 30.91, 28.3, 20.44, and $18.425 \mathrm{~mA} \mathrm{~cm}^{-2}$, respectively. The difference between the values of $J_{p h}$ and $J_{s c}$ values is attributed to the recombination loses due to Shockley-Read-Hall recombination, radiative recombination, and Auger recombination ${ }^{12}$. It is also evident from Fig. $7 \mathrm{c}$ that there is a slight improvement in $V_{o c}$, which is mainly determined by the internal dark-current response owing to the increase of $J_{s c}$. As for power conversion efficiency (PCE), it can be shown from Table 2 and power density curves in Fig. 7d that the proposed designs with dielectric two embedded NWs and single NW have better power conversion efficiencies than that of the $\mathrm{SiO}_{2}$ nano-sphere and planer based C-Si TFSC with 15.91\%, 14.48\%, $10.1 \%$, and $8.58 \%$, respectively.

The fabrication of the suggested design can be achieved by using physical vapor deposition, atomic chemical vapor deposition, and wet etching process according to the following steps shown in Fig. 8. First, a $\mathrm{Si}_{3} \mathrm{~N}_{4}$ layer is deposited with a thickness of $75 \mathrm{~nm}$ using atomic chemical vapor deposition. A P-type silicon substrate is exposed to ammonia and hexamethyldisiloxane (HMDSO) gases with flow rates of 80 and 40 SSCM, respectively ${ }^{20}$. A deposition time of $15 \mathrm{~min}$ and temperature of $825^{\circ} \mathrm{C}$ are needed to obtain a silicon nitride film of $75 \mathrm{~nm}$ thickness ${ }^{20}$. Then, a thin layer of silicon is deposited with a thickness of $100 \mathrm{~nm}$ at $1000^{\circ} \mathrm{C}$ using dichlorosilane (DCS) or Silane $\left(\mathrm{SiH}_{4}\right)$ and diborane $\left(\mathrm{B}_{2} \mathrm{H}_{6}\right)$ to obtain a heavily doped p-type silicon layer with doping concentration $5 \times 10^{17} \mathrm{~cm}^{-321,22}$. Such a layer is then annealed in vacuum at a temperature of $1000{ }^{\circ} \mathrm{C}$ for crystallization as shown in Fig. $8 b^{21-26}$. Figure $8 \mathrm{c}$ shows the deposition of the second silicon layer with a thickness of $236 \mathrm{~nm}$ on p-type silicon and $\mathrm{Si}_{3} \mathrm{~N}_{4}$ layer at a temperature of $690^{\circ} \mathrm{C}$. The substrate is annealed in vacuum at $1000{ }^{\circ} \mathrm{C}$ for 30 min to achieve fully crystalline silicon film ${ }^{23}$. Next, photolithography process is used to make an isotropic etching of the required cleavages to anchor the first layer of $\mathrm{NWs}^{27}$. The NWs can be fabricated by using metalassisted chemical etching (MACE) method ${ }^{27,28}$. The Si NWs are subjected to thermally oxidizing flow to form the $\mathrm{SiO}_{2} \mathrm{NWs}$. After that, the $\mathrm{SiO}_{2} \mathrm{NWs}$ are horizontally transferred by pressing NWs substrate vertically onto the $\langle 110\rangle$ crystalline silicon substrate as shown in Fig. $8 \mathrm{~d}^{27}$. The $\mathrm{SiO}_{2} \mathrm{NWs}$ can be aligned to silicon cleavage through spinning process along the surface of the C-Si layer as revealed from Fig. $8 \mathrm{e}^{27,29}$. An additional silicon layer of $100 \mathrm{~nm}$ thickness is deposited and annealed to obtain the C-Si layer. Then, the isotropic etching and spinning process are repeated for positioning the second batch of the $\mathrm{SiO}_{2} \mathrm{NWs}$.

A layer of Si with thickness of $464 \mathrm{~nm}$ is next deposited using argon gas and is annealed in vacuum at $1000^{\circ} \mathrm{C}$ for $30 \mathrm{~min}^{23}$. Additionally, $\mathrm{n}$-thin layer of silicon is deposited with a thickness of $100 \mathrm{~nm}$ at $1000^{\circ} \mathrm{C}$ using dichlorosilane (DCS), and phosphine $\left(\mathrm{PH}_{3}\right)$ as $\mathrm{N}$-dopants with doping concentration of $1 \times 10^{19} \mathrm{~cm}^{-322}$.

Finally, an aluminum layer is deposited on sacrificial silicon substrate ${ }^{30}$ or on polyethylene terephthalate (PET) layer ${ }^{31}$. The grating can be etched using mold-assisted chemical etching to achieve the optimized dimension mentioned in Table $1^{32,33}$. After that, the aluminum grating layer is transferred to the proposed solar cell using flip transfer method ${ }^{34}$. Such sacrificial layer is later exposed to $\mathrm{KOH}$ for removal. 


\section{Conclusion}

A novel design of TFC-Si-SC with embedded dielectric NWs is presented in order to improve the light-harvesting efficiency. The performance of the suggested design is optimized using PSO technique to maximize the light absorption through the active layer. The optimized SC offers photocurrent density of $32.9 \mathrm{~mA} \mathrm{~cm}^{-2}$ and $30.2 \mathrm{~mA} \mathrm{~cm}^{-2}$ using single/double NWs, respectively. In addition, corresponding power conversion efficiencies of $14.48 \%$ and $15.91 \%$, are achieved. Therefore, this work shows the ability of using volume scattering of embedded dielectric NWs for increasing the light trapping and power conversion efficiencies in TFSC.

Received: 22 May 2020; Accepted: 28 August 2020

Published online: 16 October 2020

\section{References}

1. Obayya, S. S. A., Areed, N. F. F., Hameed, M. F. O. \& Abdelrazik, M. H. Optical nano-antennas for energy harvesting. Renew. Altern. Energy https://doi.org/10.4018/978-1-5225-1671-2.ch006 (2017).

2. Laboratory, N. R. E. Best Research-Cell Efficiency Chart. https://www.nrel.gov/pv/cell-efficiency.html (2019).

3. Hussein, M., Swillam, M. A., Obayya, S. \& Farahat, M. Electrical characteristics of silicon nanowires solar cells with surface roughness. In Quantum Dots and Nanostructures: Growth, Characterization, and Modeling XV (eds Huffaker, D. L. \& Eisele, H.) Vol 9 (SPIE, Bellingham, 2018). https://doi.org/10.1117/12.2290906.

4. Mahmoud, A. H. K. et al. Optoelectronic performance of a modified nanopyramid solar cell. J. Opt. Soc. Am. B 36, 357 (2019).

5. Abdel-Latif, G. Y., Hameed, M. F. O., Hussein, M., Abdel Razzak, M. \& Obayya, S. S. A. Characteristics of highly efficient starshaped nanowires solar cell. J. Photon. Energy 8, 1 (2018).

6. Nunomura, S., Minowa, A., Sai, H. \& Kondo, M. Mie scattering enhanced near-infrared light response of thin-film silicon solar cells. Appl. Phys. Lett. 97, 2012-2015 (2010).

7. Mopurisetty, S. M., Bajaj, M., Sathaye, N. D. \& Ganguly, S. Coupled optical and electrical analysis for thin-film solar cells with embedded dielectric nanoparticles. Appl. Phys. Lett. 106, 1-5 (2015).

8. Yang, Z. et al. Broadband and wide-angle light harvesting by ultra-thin silicon solar cells with partially embedded dielectric spheres. Opt. Lett. 41, 1329 (2016).

9. Nagel, J. R. \& Scarpulla, M. A. Design principles for light trapping in thin silicon films with embedded dielectric nanoparticles. Prog. Photovolt. Res. Appl. 21, 319-325 (2013).

10. Nagel, J. R. \& Scarpulla, M. A. Enhanced absorption in optically thin solar cells by scattering from embedded dielectric nanoparticles. Opt. Express 18, A139 (2010).

11. Lumerical: High-Performance Photonic Simulation Software. www.lumerical.com.

12. Abdel-Latif, G. Y., Hameed, M. F. O., Hussein, M., Razzak, M. A. \& Obayya, S. S. A. Electrical characteristics of funnel-shaped silicon nanowire solar cells. J. Photon. Energy 7, 1-15 (2017).

13. Obayya, S. S. A., Rahman, B. M. A. \& El-Mikati, H. A. Full-vectorial finite-element beam propagation method for nonlinear directional coupler devices. IEEE J. Quantum. Electron. 36, 556-562 (2000).

14. Obayya, S. S. A. Novel finite element analysis of optical waveguide discontinuity problems. J. Light. Technol. 22, 1420-1425 (2004).

15. Obayya, S. S. A., Somasiri, N., Rahman, B. M. A. \& Grattan, K. T. V. Full vectorial finite element modeling of novel polarization rotators. Opt. Quantum Electron. 35, 297-312 (2003).

16. Palik, E. D. Handbook of Optical Constants of Solids. Handbook of Optical Constants of Solids (Elsevier, New York, 1985). https:// doi.org/10.1016/C2009-0-20920-2.

17. Liscidini, M., Bozzola, A. \& Andreani, L. Photonic light-trapping and Lambertian limit in thin film silicon solar cells. Opt. Soc. Am. https://doi.org/10.1364/CLEO_AT.2012.JTh2A.70 (2012).

18. Heidarzadeh, H. \& Tavousi, A. Performance enhancement methods of an ultra-thin silicon solar cell using different shapes of back grating and angle of incidence light. Mater. Sci. Eng. B Solid-State Mater. Adv. Technol. 240, 1-6 (2019).

19. Yang, Z., Li, X., Wu, S., Gao, P. \& Ye, J. High-efficiency photon capturing in ultrathin silicon solar cells with front nanobowl texture and truncated-nanopyramid reflector. Opt. Lett. 40, 1077 (2015).

20. Jhansirani, K., Dubey, R. S., More, M. A. \& Singh, S. Deposition of silicon nitride films using chemical vapor deposition for photovoltaic applications. Results Phys. 6, 1059-1063 (2016).

21. Bailly, M. S., Karas, J., Jain, H., Dauksher, W. J. \& Bowden, S. Damage-free laser patterning of silicon nitride on textured crystalline silicon using an amorphous silicon etch mask for Ni/Cu plated silicon solar cells. Thin Solid Films 612, 243-249 (2016).

22. Chen, Y. et al. Nanostructured dielectric layer for ultrathin crystalline silicon solar cells. Int. J. Photoenergy 2017, 1-6 (2017).

23. Bailey, L. R. et al. High rate amorphous and crystalline silicon formation by pulsed DC magnetron sputtering deposition for photovoltaics. Phys. Status Solidi Appl. Mater. Sci. 212, 42-46 (2015).

24. Su, C.-J., Tsai, T.-I., Lin, H.-C., Huang, T.-Y. \& Chao, T.-S. Low-temperature poly-Si nanowire junctionless devices with gate-allaround TiN/ $\mathrm{Al}_{2} \mathrm{O}_{3}$ stack structure using an implant-free technique. Nanosc. Res. Lett. 7, 339 (2012).

25. Yokoyama, S., Ohba, K., Kawamura, K., Kidera, T. \& Nakajima, A. Low-temperature selective deposition of silicon on silicon nitride by time-modulated disilane flow and formation of silicon narrow wires. Appl. Phys. Lett. 79, 494-496 (2001).

26. Gui, C., Albers, H., Gardeniers, J. G. E., Elwenspoek, M. \& Lambeck, P. V. Fusion bonding of rough surfaces with polishing technique for silicon micromachining. Microsyst. Technol. 3, 122-128 (1997).

27. Zhang, D. et al. Horizontal transfer of aligned Si nanowire arrays and their photoconductive performance. Nanosc. Res. Lett. 9 , 1-5 (2014).

28. Peng, K., Yan, Y., Gao, S. \& Zhu, J. Dendrite-assisted growth of silicon nanowires in electroless metal deposition. Adv. Funct. Mater. 13, 127-132 (2003).

29. Nagel, J. R. \& Scarpulla, M. A. Enhanced light absorption in thin film solar cells with embedded dielectric nanoparticles: Induced texture dominates Mie scattering. Appl. Phys. Lett. 102, 1-5 (2013).

30. Levine, I. et al. Epitaxial two dimensional aluminum films on silicon (111) by ultra-fast thermal deposition. J. Appl. Phys. 111, 124320 (2012).

31. Dunn, T. Overprint varnishes and coatings. In Flexible Packaging 227-232 (Elsevier, New York, 2015). https://doi.org/10.1016/ B978-0-323-26436-5.00027-8.

32. Lee, W. The anodization of aluminum for nanotechnology applications. JOM 62, 57-63 (2010).

33. Lai, K.-L., Hon, M.-H. \& Leu, I.-C. Fabrication of ordered nanoporous anodic alumina prepatterned by mold-assisted chemical etching. Nanosc. Res. Lett. 6, 157 (2011).

34. Zhang, K., Seo, J.-H., Zhou, W. \& Ma, Z. Fast flexible electronics using transferrable silicon nanomembranes. J. Phys. D. Appl. Phys. 45, 143001 (2012). 


\section{Acknowledgements}

The authors acknowledge the financial support provided by Academy of Scientific Research and Technology (ASRT) under project title Knowledge and Technology Alliance (KTA-ASRT).

\section{Author contributions}

M.A.E., M.H., M.F.O.H., and S.S.A.O. have proposed the idea. M.A.E. has done the simulations of the reported SC. M.A.E., M.H., M.F.O.H., and S.S.A.O. are contributed in the analysis, discussion and writing the paper.

\section{Competing interests}

The authors declare no competing interests.

\section{Additional information}

Correspondence and requests for materials should be addressed to M.F.O.H. or S.S.A.O.

Reprints and permissions information is available at www.nature.com/reprints.

Publisher's note Springer Nature remains neutral with regard to jurisdictional claims in published maps and institutional affiliations.

(c) (i) Open Access This article is licensed under a Creative Commons Attribution 4.0 International License, which permits use, sharing, adaptation, distribution and reproduction in any medium or format, as long as you give appropriate credit to the original author(s) and the source, provide a link to the Creative Commons licence, and indicate if changes were made. The images or other third party material in this article are included in the article's Creative Commons licence, unless indicated otherwise in a credit line to the material. If material is not included in the article's Creative Commons licence and your intended use is not permitted by statutory regulation or exceeds the permitted use, you will need to obtain permission directly from the copyright holder. To view a copy of this licence, visit http://creativecommons.org/licenses/by/4.0/.

(c) The Author(s) 2020 